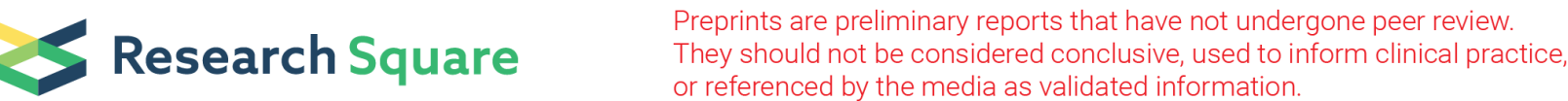

\section{Longitudinal comparison of anxiety and depression between idiopathic pulmonary fibrosis and other interstitial lung diseases: a prospective cohort study}

\section{Won Bae}

Seoul National University Hospital

Jaeyoung Cho

Seoul National University Hospital

Jinwoo Lee

Seoul National University Hospital

\section{Young Sik Park}

Seoul National University Hospital

\section{Chang-Hoon Lee}

Seoul National University Hospital

\section{Sang-Min Lee}

Seoul National University Hospital

\section{Chul-Gyu Yoo}

Seoul National University Hospital

\section{Young Whan Kim}

Seoul National University Hospital

Sun Mi Choi ( $\nabla$ sunmich81@gmail.com )

https://orcid.org/0000-0002-0742-6085

\section{Research}

Keywords: Interstitial Lung Disease, Lung fibrosis, Quality of Life

Posted Date: June 19th, 2020

DOI: https://doi.org/10.21203/rs.3.rs-36517/v1

License: (c) (i) This work is licensed under a Creative Commons Attribution 4.0 International License. Read Full License 


\section{Abstract \\ Background and objective:}

Few studies have investigated the differences in the incidence of anxiety and depression among the interstitial lung diseases (ILDs). We evaluated the differences in the incidence of anxiety and depression between idiopathic pulmonary fibrosis (IPF) and non-IPF ILD, and the changes after a 1-year follow-up period.

\section{Methods}

The study participants were patients included in a prospective ILD cohort of Seoul National University Hospital between March 2013 and August 2018. Clinical variables were recorded at baseline and at 1 year. The Hospital Anxiety and Depression Scale was used to assess patient anxiety and depression at baseline and at 1-year follow-up.

\section{Results}

A total of 224 patients in the cohort participated in the study (154 [68.8\%] with IPF and 70 [31.2\%] with non-IPF ILD). Among them, 111 patients completed a follow-up Hospital Anxiety and Depression Scale questionnaire 1 year later (77 in the IPF group, 34 in the non-IPF group). In the IPF group, $20.8 \%$ and $27.3 \%$ of patients suffered from anxiety and $29.9 \%$ and $31.2 \%$ suffered from depression at baseline and 1-year follow-up, respectively. In the non-IPF group, $14.3 \%$ and $23.5 \%$ of patients suffered from anxiety and $24.3 \%$ and $17.6 \%$ suffered from depression at baseline and 1-year follow-up, respectively. Total score on the St. George's Respiratory Questionnaire at baseline was associated with depression both at baseline (odds ratio 1.05; 95\% confidence interval 1.02-1.08) and at 1-year follow-up (odds ratio 1.03; 95\% confidence interval 1.00-1.05), even after adjusting other factors. The interaction of prevalence change of anxiety and depression at baseline and 1-year follow-up between the IPF group and the nonIPF ILD group were not statistically significant (p-value 0.878 for anxiety and 0.376 for depression, respectively).

\section{Conclusion}

The prevalence of anxiety and depression at baseline and at 1-year follow-up were not significantly different between patients with IPF and non-IPF ILD. St. George's Respiratory Questionnaire total score at baseline was associated with depression at baseline and at 1-year follow-up.

\section{Introduction}


Many conditions fall under the category of interstitial lung disease (ILD). Idiopathic pulmonary fibrosis (IPF), the most common form of idiopathic interstitial pneumonia [1] is a specific form of chronic, progressive fibrosing ILD of unknown cause occurring in adults. The condition is associated with poor prognosis and a median survival of 2.5-3.5 years [2]. Treatment and prognosis of non-IPF ILD is different for each disease. Systemic steroid therapy is recommended to treat idiopathic nonspecific interstitial pneumonia, and 5-year survival has been reported to be greater than 70\% [3-5]. Cryptogenic organizing pneumonia also has good response to systemic steroid therapy $[6,7]$. Less than $5 \%$ of patients with cryptogenic organizing pneumonia progress to acute respiratory failure or death [8-10]. Connective tissue disease-associated ILD has various prognoses based on the causative connective tissue disease. Interstitial lung disease has been found to contribute about $13 \%$ to the excess mortality of patients with rheumatoid arthritis-related ILD (RA-ILD) compared with the general population [11]. The 10-year survival rate after diagnosis of systemic sclerosis-related ILD has been reported in the range of $29 \%-69 \%$. In $45 \%-55 \%$ of patients, deterioration of pulmonary function is confirmed within the first 3 years, and about $16 \%$ of patients develop severe restrictive pulmonary disease [12]. The 5-year survival rate of Sjögren's syndrome-related ILD has been reported to be $84 \%$ [13].

Depression is more common in patients with chronic disease than in healthy people [14]. Anxiety and depression might be strengthened by the uncertain course of critical illness and a lack of clarity about the prognosis [15]. Therefore, anxiety and depression are common in patients with IPF or ILD. One recent study observed that about one-quarter of patients with IPF had depression and anxiety [16]. Dyspnea and comorbidity contribute to anxiety and depression in ILD [17]. Past studies have demonstrated that depression and anxiety are associated with health-related quality of life, health status, and reduced forced vital capacity (FVC); however, no significant differences have been found in survival rate and hospitalization $[16,18,19]$. One prospective study found that depressive symptoms in patients with ILD were persistent, and presence of depression at initial evaluation was the most powerful predictor of depression severity at follow-up [18]. However, anxiety had not been assessed in that study. Few studies have evaluated the differences in prevalences of anxiety and depression between patients with IPF and non-IPF ILD. In this study, we evaluated the prevalences of depression and anxiety in patients with IPF and non-IPF ILD and analyzed the changes in prevalence after 1 year, using a prospective cohort.

\section{Methods}

We recruited patients from the prospective ILD registry in Seoul National University Hospital in Korea between March 2014 and August 2018. All patients provided written informed consent. This study was approved by the Institutional Review Board and Ethics Committee of Seoul National University Hospital (number: NCT03238989). Among the patients of the ILD registry, those who completed the) at baseline and 1-year follow-up or at baseline were included in the analysis.

Idiopathic pulmonary fibrosis was diagnosed according to the 2011 consensus of the American Thoracic Society, European Respiratory Society, Japanese Respiratory Society, and Latin American Thoracic Association [2] and non-IPF ILD was defined as all ILDs except IPF. The HADS, which was a primary 
outcome, was used to assess depression and anxiety. The questionnaire had been validated by several studies, and we used a validated Korean version [20-22]. The HADS consists of 14 questions; 7 questions on depression (HADS-D) and the other 7 on anxiety (HADS-A). Scores for each subscale range from 0 to 21 .

Other study variables were as follows: age, sex, smoking history, comorbidity, St. George's Respiratory Questionnaire (SGRQ) score, modified Medical Research Council (mMRC) dyspnea scale score, six-minute walk test performance, FVC, diffusing capacity of the lungs for carbon monoxide (DLCO), and gender-agephysiology (GAP) index. Pulmonary function tests (FVC and DLCO) were carried out by trained

technicians according to standardized American Thoracic Society guidelines [23]. The GAP index for each patient was calculated according to methods described by Ley, et al [24]. The SGRQ score, FVC, and DLCO were measured at the 1-year follow-up.

Continuous variables were compared using the independent Student's $t$-test, and categorical variables were compared using the Chi-square test. Logistic regression was used to identify the factors influencing the presence of anxiety or depression on baseline status. The generalized estimating equation was conducted to identify the factors affecting the presence of anxiety or depression, at baseline and the 1year follow-up. Statistical analyses were performed using R version 3.4.4 (The R Foundation for Statistical Computing, Vienna, Austria, https://www.r-project.org). The level of significance was set at 0.05 .

\section{Results}

\section{Participant characteristics}

Two-hundred fifty-three patients were recruited from the ILD registry. Twenty-three patients were excluded from the study due to incomplete HADS questionnaires. Six were excluded due to uncertainty of diagnosis. Therefore, the data of 224 patients were eligible for analysis at baseline. Of these 224 patients, 154 were diagnosed with IPF, and 70 were diagnosed with non-IPF ILD. In the patients with non-IPF ILD, there were $26(37.1 \%)$ with connective tissue disease-related ILD, 11 with nonspecific interstitial pneumonia (15.7\%), and 1 with cryptogenic organizing pneumonia (1.4\%). One hundred eleven patients completed the HADS questionnaire 1 year after enrollment in the registry (at 1-year follow-up). Of these patients, 77 had IPF, and 34 had non-IPF ILD (Figure 1).

At baseline, there were 118 (76.6\%) males in the IPF group and 31 (44.3\%) males in the non-IPF ILD group. Average age in the IPF and non-IPF ILD groups were $71.4 \pm 7.8$ and $61.9 \pm 14.1$, respectively. Compared with the IPF group, there were more patients in the non-IPF ILD group who had never smoked (56.7\% vs. $30.5 \%)$. Comorbidities such as diabetes mellitus, hypertension, liver disease, history of pulmonary tuberculosis, gastrointestinal disease, brain vascular disease, articular disease, heart disease, and cancer were similar between the two groups. Compared with the non-IPF ILD group, SGRQ symptom scores were higher in the IPF group ( $41.9 \pm 22.1$ vs. $34.5 \pm 20.5, p=0.02)$. St. George's Respiratory Questionnaire activity scores $(40.8 \pm 28.4$ and $36.9 \pm 28.4$ in IPF and non-IPF group, $p=0.34)$, impacts 
scores $(21.3 \pm 22.7$ and $17.2 \pm 19.8, p=0.203)$, and total scores $(31.2 \pm 22.1$ and $26.4 \pm 20.6, p=0.133)$ were not significantly different between the two groups. Compared with the non-IPF ILD group, the GAP index was higher in the IPF group ( $2.8 \pm 1.3$ vs. $1.9 \pm 1.3, p<0.001)$. Six-minute walk test performance $(m)$ was $410.7 \pm 108.6$ and $434.1 \pm 96.5$ in the IPF and non-IPF groups, respectively, $(p=0.376)$. Modified Medical Research Council dyspnea scale scores were not significantly different between the two groups. Forced vital capacity in liters $(2.7 \pm 0.8$ and $2.6 \pm 1.0, p=0.378)$, FVC percent predicted $(78.8 \pm 17.1$ and $80.6 \pm 21.6$, $\mathrm{p}=0.553$ ), and DLCO were also not significantly different between the two groups (Table 1).

\section{Prevalences of anxiety and depression}

Prevalences of anxiety and depression of patients with IPF at baseline and at 1 year were $20.9 \%(95 \%$ confidence interval [Cl], 14.8-28.2), 29.9\% (95\% Cl, 22.9-37.9), 27.3\% (95\% Cl, 18.0-38.8), and 31.2\% (95\% $\mathrm{Cl}, 21.4-42.9)$, respectively. In the non-IPF group, prevalences of anxiety and depression were $14.3 \%$ (95\% $\mathrm{Cl}, 7.4-25.2)$ and $24.3 \%(95 \% \mathrm{Cl}, 15.2-36.3)$, respectively, at baseline. One year after, the prevalences of anxiety and depression in the non-IPF group were $23.5 \%(95 \% \mathrm{Cl}, 11.4-41.6)$ and $17.7 \%(95 \% \mathrm{Cl}, 7.4-35.2)$, respectively (Table 2 ).

The prevalence of anxiety increased after 1 year in both the IPF and non-IPF ILD groups, and the p-value for interaction was 0.878 . The prevalence of depression in the non-IPF ILD group decreased after 1 year, and the difference in prevalence between the IPF group and non-IPF ILD group increased; however, the pvalue for interaction was 0.376 (Figure 2).

\section{Factors associated with anxiety and depression}

At baseline, whether the patient had been diagnosed with IPF or non-IPF ILD was not associated with anxiety and depression (odds ratio [OR] 1.65; 95\% Cl 0.71-3.88 in anxiety; OR 1.27; 95\% Cl 0.64-2.53 in depression). This finding was the same even after sex, age, whether the patient had been diagnosed with IPF or non-IPF ILD, SGRQ total score at baseline, FVC percent predicted at baseline, DLCO percent predicted at baseline, mMRC dyspnea scale score, and six-minute walk test performance were adjusted (OR 1.72; 95\% Cl 0.64-4.63 in anxiety; OR 1.18; 95\% Cl 0.52-2.70 in depression). St. George's Respiratory Questionnaire total score at baseline was significantly associated with anxiety and depression at baseline after adjusting the above-mentioned factors (OR 1.72; 95\% Cl 1.01-1.05 in anxiety; OR 1.04; 95\% $\mathrm{Cl}$ 1.02-1.06 in depression) (Table 3). Whether the patient had been diagnosed with IPF or non-IPF ILD was not associated with anxiety and depression after 1 year (OR 1.48; 95\% $\mathrm{Cl}$ 0.54-4.10 in anxiety; OR $1.69 ; 95 \% \mathrm{Cl}$ 0.64-4.50 in depression). Only SGRQ total score at baseline was associated with depression after 1 year, after adjusting for sex, age, whether the patient had been diagnosed with IPF or non-IPF ILD, FVC percent predicted at baseline, DLCO percent predicted at baseline, mMRC dyspnea scale score at baseline, and 6-minute walk test performance at baseline (OR 1.03; 95\% $\mathrm{Cl}$ 1.00-1.05) (Table 4).

\section{Discussion}


In this study, prevalences of anxiety and depression at baseline were $20.8 \%$ and $29.9 \%$ in the IPF group, and $14.3 \%$ and $24.3 \%$ in the non-IPF ILD group, respectively. At 1-year follow-up, prevalences of anxiety and depression at baseline were $27.3 \%$ and $31.2 \%$ in the IPF group, and $23.5 \%$ and $17.6 \%$ in the non-IPF ILD group. St. George's Respiratory Questionnaire total score at baseline was associated with anxiety and depression at baseline and depression at 1-year follow-up. The proportion of patients with depression in the non-IPF ILD group decreased slightly from baseline to 1-year follow-up. However, the difference in the change in prevalence of depression between the IPF group and the non-IPF ILD group at 1-year follow-up was not statistically significant.

According to the Diagnostic and Statistical Manual of Mental Disorders, Fifth Edition, the diagnostic criteria for depression are mood swings, marked irritability or anger, decreased interest in usual activities, etc. Anxiety refers to the anticipation of future threat. This mood state is associated with muscle tension and vigilance in preparation for future danger and cautious or avoidant behaviors [25].

Psychological symptoms are associated with disease progress in severe COPD [26]. Depression negatively impacts patient quality of life by decreasing treatment compliance [27]. Idiopathic pulmonary fibrosis is associated with poor prognosis; therefore, anxiety and depression are common in patients with IPF $[18,19]$. The prevalences of anxiety and depression in patients with IPF in the present study were similar to those in other studies [28]. However, there were no significant differences in the prevalences of anxiety and depression between patients with IPF and patients with non-IPF ILDs.

Dyspnea and depression influence one another. Depressive symptoms are caused by dyspnea, and the awareness of dyspnea is worsened by depressive symptoms [18]. Some depressive symptoms, such as dyspnea, fatigue, appetite, sleep, and concentration, can overlap with pulmonary symptoms [29]. In the present study, there were no significant differences in mMRC dyspnea scale score and six-minute walk test performance between the IPF group and non-IPF ILD group (Table 1). Moreover, mMRC dyspnea scale score and six-minute walk test performance were associated with anxiety and depression independently of whether the patient had been diagnosed with IPF or non-IPF ILD (data not shown). This finding indicates that anxiety and depression were related to dyspnea in all ILD patients.

Depression has been found to be significantly associated with health-related quality of life [19]. The present study demonstrated that anxiety is influenced by health-related quality of life, as measured by the SGRQ, in both patients with IPF and patients with non-IPF ILD. Although the SGRQ was not specifically developed for use in patients with IPF, its psychometric properties have been determined to be adequate, and it can be a useful measure of health-related quality of life in these patients [30]. The SGRQ total score at baseline was found to be related to anxiety and depression at baseline in both groups. Our study suggests that the SGRQ can also aid in the psychometric testing of patients with non-IPF ILD.

In one study, it was observed that the tendencies toward anxiety and depression were maintained over 1 year [31]. In another study on the impact of palliative care in patients with IPF, depression increased from baseline to the 3-and 6-month follow-ups [32]. In our study, the prevalence of anxiety increased in both groups, and the prevalence of depression increased in the IPF group but decreased in the non-IPF 
ILD group from baseline to 1-year follow-up. Whether the patient had been diagnosed with IPF or non-IPF ILD was not found to be associated with anxiety and depression after 1-year follow-up. The changes in prevalence of anxiety and depression after 1 year were not significantly different between the IPF and non-IPF ILD groups; the p-value for interaction was 0.878 and 0.376 in anxiety and depression, respectively (Fig. 2). Dyspnea was found to be associated with persistent anxiety and depression in both groups over 1 year in the univariate analysis but not in multivariate analysis. It was similar results with other study [31]. In the present study, SGRQ total score at baseline was related to depression at baseline and at 1-year follow-up, regardless of whether patients had IPF or non-IPF ILD. Interstitial lung disease has a long-term effect on health-related quality of life. Therefore, it is important to comprehensively evaluate patients with ILD.

One previous study demonstrated that depression and anxiety were not related to prognosis in patients with IPF [16]. The role of palliative care in patients with IPF is unclear $[32,33]$. The present study included not only patients with IPF, but also patients with non-IPF ILDs. In addition, the patients were followed up prospectively for 1 year. However, a 1-year period is a relatively short amount of time to investigate changes in anxiety and depression in patients with ILD. Further studies that evaluate the changes in and impact of anxiety and depression on clinical outcomes in patients with ILD are warranted.

\section{Conclusion}

Anxiety and depression were commonly observed in patients with ILD. The prevalences of anxiety and depression at baseline and at 1-year follow-up were not significantly different between patients with IPF and patients with non-IPF ILD. Quality of life at baseline was associated with depression at baseline and at 1-year follow-up, regardless of whether the patient had been diagnosed with IPF or non-IPF ILD.

\section{Abbreviations}

DLCO: Diffusing capacity of the lungs for carbon monoxide; FVC: Forced vital capacity; GAP: Gender-agephysiology; HADS: Hospital anxiety and depression scale; ILD: Interstitial lung disease; IPF: Idiopathic pulmonary fibrosis; mMRC: Modified medical research council; RA-ILD: Rheumatoid arthritis-related ILD; SGRQ: St. George's respiratory questionnaire.

\section{Declarations}

\section{Ethics approval and consent to participate}

All patients provided written informed consent. This study was approved by the Institutional Review Board and Ethics Committee of Seoul National University Hospital (number: NCT03238989).

\section{Availability of data and materials}


The datasets used and/or analysed during the current study are available from the corresponding author on reasonable request.

\section{Consent for publication}

Not applicable

\section{Competing interests}

The authors declare that they have no competing interests

\section{Funding}

The authors have reported that no funding was received for this study.

\section{Authors' contributions}

All authors had full access to the data in this study and take complete responsibility for the integrity of the data and accuracy of the data analysis. Sun Mi Choi designed the study, data interpretation, and provided critical review and revision of the manuscript for intellectual content. Won Bae contributed to statistical analysis, data interpretation and drafted the initial manuscript. Chang-Hoon Lee conducted to statistical analysis and contributed to the study design, data interpretation, and provided critical review and revision of the manuscript for intellectual content. Jaeyoung Cho, Jinwoo Lee, Young Sik Park, SangMin Lee, Chul-Gyu Yoo and Young Whan Kim conducted to data interpretation and study supervision. All the authors approved the final manuscript as submitted.

\section{Acknowledgements}

Not applicable

\section{References}

1 Dan L. Longo, Dennis L. Kasper, J.Larry Jameson, Anthony S. Fauci, Stephen L. Hauser, Joseph Loscalzo. Harrison's Principles of Internal Medicine. 18th ed. McGraw-Hill, New York, 2011; 2160-2170. 
2 Raghu G, Collard HR, Egan JJ, Martinez FJ, Behr J, Brown KK, Colby TV, Cordier JF, Flaherty KR, Lasky JA, Lynch DA, Ryu JH, Swigris JJ, Wells AU, Ancochea J, Bouros D, Carvalho C, Costabel U, Ebina M, Hansell DM, Johkoh T, Kim DS, King TE, Jr., Kondoh Y, Myers J, Muller NL, Nicholson AG, Richeldi L, Selman M, Dudden RF, Griss BS, Protzko SL, Schunemann HJ. An official ATS/ERS/JRS/ALAT statement: idiopathic pulmonary fibrosis: evidence-based guidelines for diagnosis and management. Am J Respir Crit Care Med. 2011; 183: 788-824.

3 Travis WD, Hunninghake G, King TE, Jr., Lynch DA, Colby TV, Galvin JR, Brown KK, Chung MP, Cordier JF, du Bois RM, Flaherty KR, Franks TJ, Hansell DM, Hartman TE, Kazerooni EA, Kim DS, Kitaichi M, Koyama T, Martinez FJ, Nagai S, Midthun DE, Müller NL, Nicholson AG, Raghu G, Selman M, Wells A. Idiopathic nonspecific interstitial pneumonia: report of an American Thoracic Society project. Am J Respir Crit Care Med. 2008; 177: 1338-47.

4 Park IN, Jegal Y, Kim DS, Do KH, Yoo B, Shim TS, Lim CM, Lee SD, Koh Y, Kim WS, Kim WD, Jang SJ, Kitaichi M, Nicholson AG, Colby TV. Clinical course and lung function change of idiopathic nonspecific interstitial pneumonia. Eur Respir J. 2009; 33: 68-76.

5 Lee JY, Jin SM, Lee BJ, Chung DH, Jang BG, Park HS, Lee SM, Yim JJ, Yang SC, Yoo CG, Han SK, Shim YS, Kim YW. Treatment response and long term follow-up results of nonspecific interstitial pneumonia. J Korean Med Sci. 2012; 27: 661-7.

6 Fonseca AL, Meruje M, Barata F, Martins Y. Bronchiolitis obliterans organizing pneumoniaexperience of a pulmonology ward. Rev Port Pneumol. 2007; 13: 301-18.

7 Okada F, Ando Y, Honda K, Tanoue S, Matsumoto S, Mori H. Comparison of pulmonary CT findings and serum KL-6 levels in patients with cryptogenic organizing pneumonia. $\mathrm{Br} J$ Radiol. 2009; 82: 212-8.

8 Lazor R, Vandevenne A, Pelletier A, Leclerc P, Court-Fortune I, Cordier JF. Cryptogenic organizing pneumonia. Characteristics of relapses in a series of 48 patients. The Groupe d'Etudes et de Recherche sur les Maladles "Orphelines" Pulmonaires (GERM"O"P). Am J Respir Crit Care Med. 2000; 162: 571-7.

9 Cazzato S, Zompatori M, Baruzzi G, Schiattone ML, Burzi M, Rossi A, Ratta L, Terzuolo G, Falcone F, Poletti V. Bronchiolitis obliterans-organizing pneumonia: an Italian experience. Respir Med 2000; 94: 7028.

10 Oymak FS, Demirbas HM, Mavili E, Akgun H, Gulmez I, Demir R, Ozesmi M. Bronchiolitis obliterans organizing pneumonia. Clinical and roentgenological features in 26 cases. Respiration. 2005; 72: 254-62.

11 Bongartz T, Nannini C, Medina-Velasquez YF, Achenbach SJ, Crowson CS, Ryu JH, Vassallo R, Gabriel SE, Matteson EL. Incidence and mortality of interstitial lung disease in rheumatoid arthritis: a population-based study. Arthritis Rheum. 2010; 62: 1583-91. 
12 Steen VD, Conte C, Owens GR, Medsger TA, Jr. Severe restrictive lung disease in systemic sclerosis. Arthritis Rheum. 1994; 37: 1283-9.

13 Sarkar PK, Patel N, Furie RA, Talwar A. Pulmonary manifestations of primary Sjögren's syndrome. Indian J Chest Dis Allied Sci. 2009; 51: 93-101.

14 Moussavi S, Chatterji S, Verdes E, Tandon A, Patel V, Ustun B. Depression, chronic diseases, and decrements in health: results from the World Health Surveys. Lancet. 2007; 370: 851-8.

15 Lindell KO, Liang Z, Hoffman LA, Rosenzweig MQ, Saul MI, Pilewski JM, Gibson KF, Kaminski N. Palliative care and location of death in decedents with idiopathic pulmonary fibrosis. Chest. 2015; 147: 423-9.

16 Lee YJ, Choi SM, Lee YJ, Cho YJ, Yoon HI, Lee JH, Lee CT, Park JS. Clinical impact of depression and anxiety in patients with idiopathic pulmonary fibrosis. PLoS One. 2017; 12: e0184300.

17 Holland AE, Fiore JF, Jr., Bell EC, Goh N, Westall G, Symons K, Dowman L, Glaspole I. Dyspnoea and comorbidity contribute to anxiety and depression in interstitial lung disease. Respirology. 2014; 19: 121521.

18 Ryerson CJ, Arean PA, Berkeley J, Carrieri-Kohlman VL, Pantilat SZ, Landefeld CS, Collard HR. Depression is a common and chronic comorbidity in patients with interstitial lung disease. Respirology. 2012; 17: 525-32.

19 Matsuda T, Taniguchi H, Ando M, Kondoh Y, Kimura T, Kataoka K, Nishimura K, Nishiyama O, Sakamoto K, Hasegawa Y. Depression Is Significantly Associated with the Health Status in Patients with Idiopathic Pulmonary Fibrosis. Intern Med. 2017; 56: 1637-44.

20 Lisspers J, Nygren A, Soderman E. Hospital Anxiety and Depression Scale (HAD): some psychometric data for a Swedish sample. Acta Psychiatr Scand. 1997; 96: 281-6.

21 Malasi TH, Mirza IA, el-Islam MF. Validation of the Hospital Anxiety and Depression Scale in Arab patients. Acta Psychiatr Scand. 1991; 84: 323-6.

22 Oh SM MK, Park DB. A Study on the Standardization of the Hospital Anxiety and Depression Scale for Koreans: A Comparison of Normal, Depressed and Anxious Groups. J Korean Neuropsychiatr Assoc. 1999; 38: 289-96.

23 Standardization of Spirometry, 1994 Update. American Thoracic Society. Am J Respir Crit Care Med. 1995; 152: 1107-36.

24 Ley B, Ryerson CJ, Vittinghoff E, Ryu JH, Tomassetti S, Lee JS, Poletti V, Buccioli M, Elicker BM, Jones KD, King TE, Jr., Collard HR. A multidimensional index and staging system for idiopathic pulmonary fibrosis. Ann Intern Med. 2012; 156: 684-91. 
25 Diagnostic and Statistical Manual of Mental Disorders, 5th Edition. American Psychiatric Association. Washington, DC, 2013;155-230.

26 Tsujimura Y, Hiramatsu T, Kojima E, Tabira K. Factors influencing the physical activity in daily life of male patients with different levels of severity of chronic obstructive pulmonary disease. J Phys Ther Sci. 2018; 30: 1251-6.

27 DiMatteo MR, Lepper HS, Croghan TW. Depression is a risk factor for noncompliance with medical treatment: meta-analysis of the effects of anxiety and depression on patient adherence. Arch Intern Med. 2000; 160: 2101-7.

28 Akhtar AA, Ali MA, Smith RP. Depression in patients with idiopathic pulmonary fibrosis. Chron Respir Dis. 2013; 10: 127-33.

29 Verma S, Cardenas-Garcia J, Mohapatra PR, Talwar A. Depression in pulmonary arterial hypertension and interstitial lung diseases. N Am J Med. Sci. 2014; 6: 240-9.

30 Swigris JJ, Esser D, Conoscenti CS, Brown KK. The psychometric properties of the St George's Respiratory Questionnaire (SGRQ) in patients with idiopathic pulmonary fibrosis: a literature review. Health Qual Life Outcomes. 2014; 12: 124.

31 Glaspole IN, Watson AL, Allan H, Chapman S, Cooper WA, Corte TJ, Ellis S, Grainge C, Goh N, Hopkins P, Keir G, Macansh S, Mahar A, Moodley Y, Reynolds PN, Ryerson CJ, Walters EH, Zappala CJ, Holland AE. Determinants and outcomes of prolonged anxiety and depression in idiopathic pulmonary fibrosis. Eur Respir J. 2017; 50.

32 Janssen K, Rosielle D, Wang Q, Kim HJ. The impact of palliative care on quality of life, anxiety, and depression in idiopathic pulmonary fibrosis: a randomized controlled pilot study. Respir Res. 2020; 21: 2.

33 Bajwah S, Ross JR, Wells AU, Mohammed K, Oyebode C, Birring SS, Patel AS, Koffman J, Higginson IJ, Riley J. Palliative care for patients with advanced fibrotic lung disease: a randomised controlled phase II and feasibility trial of a community case conference intervention. Thorax. 2015; 70 : 830-9.

\section{Tables}

Table 1. Baseline characteristics of the participants 


\begin{tabular}{|l|c|c|c|}
\hline & \multicolumn{2}{|c|}{ Diagnosis } & P-value \\
\hline & IPF $(\mathrm{n}=154)$ & Non-IPF ILD $(\mathrm{n}=70)$ & \\
\hline Male & $118(76.6 \%)$ & $31(44.3 \%)$ & $<0.001$ \\
\hline Age & $71.4 \pm 7.8$ & $61.9 \pm 14.1$ & $<0.001$ \\
\hline Smoking status & & & $<0.001$ \\
\hline current & $9(6.0 \%)$ & $8(11.9 \%)$ & \\
\hline ex & $96(63.6 \%)$ & $21(31.3 \%)$ & \\
\hline never & $46(30.5 \%)$ & $38(56.7 \%)$ & \\
\hline DM & $44(28.9 \%)$ & $12(17.6 \%)$ & 0.107 \\
\hline HTN & $58(37.9 \%)$ & $15(22.1 \%)$ & 0.031 \\
\hline Liver disease & $16(10.5 \%)$ & $7(10.3 \%)$ & 0.999 \\
\hline History of pulmonary TB & $20(13.1 \%)$ & $8(11.8 \%)$ & 0.96 \\
\hline GI disease & $20(13.1 \%)$ & $10(14.7 \%)$ & 0.332 \\
\hline Brain vascular disease & $2(1.3 \%)$ & $2(2.9 \%)$ & 0.768 \\
\hline Articular disease & $14(9.2 \%)$ & $7(10.3 \%)$ & 0.985 \\
\hline Heart disease & $19(12.4 \%)$ & $12(17.6 \%)$ & 0.41 \\
\hline Cancer & $10(6.7 \%)$ & $5(7.4 \%)$ & 0.999 \\
\hline SGRQ score & & & \\
\hline Symptom & $41.9 \pm 22.1$ & $34.5 \pm 20.5$ & 0.02 \\
\hline Activity & $40.8 \pm 28.4$ & $36.9 \pm 28.4$ & 0.34 \\
\hline Impacts & $21.3 \pm 22.7$ & $17.2 \pm 19.8$ & 0.203 \\
\hline Total & $31.2 \pm 22.1$ & $26.4 \pm 20.6$ & 0.133 \\
\hline GAP score & $2.8 \pm 1.3$ & $1.9 \pm 1.3$ & $<0.001$ \\
\hline GAP stage & & & 0.225 \\
\hline 1 & $108(74.0 \%)$ & $51(85.0 \%)$ & \\
\hline 2 & $34(23.3 \%)$ & $9(15.0 \%)$ & \\
\hline 3 & $4(2.7 \%)$ & 0 & \\
\hline 6 -minute walk test $(m)$ & $410.7 \pm 108.6$ & $434.1 \pm 96.5$ & 0.376 \\
\hline mMRC dyspnea scale & & & 0.103 \\
\hline 0 & $36(23.8 \%)$ & $22(32.4 \%)$ & \\
\hline 1 & $72(47.7 \%)$ & $33(48.5 \%)$ & \\
\hline 2 & $38(25.2 \%)$ & $8(11.8 \%)$ & \\
\hline 3 & $5(3.3 \%)$ & $5(7.4 \%)$ & \\
\hline FVC (liter) & $2.7 \pm 0.8$ & $2.6 \pm 1.0$ & 0.378 \\
\hline FVC (pred, \%) & $78.8 \pm 17.1$ & $80.6 \pm 21.6$ & 0.553 \\
\hline DLCO & $11.9 \pm 10.5$ & $12.0 \pm 4.5$ & 0.879 \\
\hline DLCO (pred, \%) & $64.1 \pm 19.4$ & $62.9 \pm 18.2$ & 0.684 \\
\hline & & & \\
\hline & & & \\
\hline & & & \\
\hline & & & \\
\hline
\end{tabular}

DM = diabetes mellitus; FVC (liter) = forced vital capacity in liters; FVC (pred \%) = forced vital capacity percent predicted; GAP = gender-age-physiology; GI = gastrointestinal; $\mathrm{HTN}=$ hypertension; ILD = interstitial lung disease; IPF = idiopathic pulmonary fibrosis; $\mathrm{mMRC}=$ modified Medical Research Council dyspnea scale; SGRQ = St. George's Respiratory Questionnaire; TB = tuberculosis.

Continuous data are presented as mean \pm SD, and categorical data are presented as number (\%). 
Table 2. Prevalence of anxiety and depression

\begin{tabular}{|c|c|c|c|c|c|c|c|c|}
\hline & \multicolumn{4}{|c|}{ Anxiety } & \multicolumn{4}{|c|}{ Depression } \\
\hline & \multicolumn{2}{|c|}{ IPF } & \multicolumn{2}{|c|}{ Non-IPF ILD } & \multicolumn{2}{|c|}{ IPF } & \multicolumn{2}{|c|}{ Non-IPF ILD } \\
\hline & Prevalence* & $95 \% \mathrm{Cl}$ & Prevalence* & $95 \% \mathrm{Cl}$ & Prevalence* & $95 \% \mathrm{Cl}$ & Prevalence* & $\begin{array}{c}95 \% \\
\mathrm{Cl}\end{array}$ \\
\hline Baseline & 20.9 & $\begin{array}{l}14.8- \\
28.2\end{array}$ & 14.3 & $\begin{array}{l}7.4- \\
25.2\end{array}$ & 29.9 & $\begin{array}{l}22.9- \\
37.9\end{array}$ & 24.3 & $\begin{array}{l}15.2- \\
36.3\end{array}$ \\
\hline 1 year & 27.3 & $\begin{array}{l}18.0- \\
38.8\end{array}$ & 23.5 & $\begin{array}{l}11.4- \\
41.6\end{array}$ & 31.2 & $\begin{array}{l}21.4- \\
42.9\end{array}$ & 17.7 & $\begin{array}{r}7.4- \\
35.2\end{array}$ \\
\hline
\end{tabular}

$\mathrm{Cl}$ = confidence interval; ILD = interstitial lung disease; IPF = idiopathic pulmonary fibrosis.

*Prevalence is expressed as \%.

Table 3. Factors associated with anxiety and depression at baseline

\begin{tabular}{|l|c|c|c|c|}
\hline & \multicolumn{2}{|c|}{ Anxiety } & \multicolumn{2}{c|}{ Depression } \\
\hline & $\begin{array}{c}\text { Unadjusted OR } \\
(95 \% \mathrm{Cl})\end{array}$ & $\begin{array}{c}\text { Adjusted OR } \\
(95 \% \mathrm{Cl})\end{array}$ & $\begin{array}{c}\text { Unadjusted OR } \\
(95 \% \mathrm{Cl})\end{array}$ & $\begin{array}{c}\text { Adjusted OR } \\
(95 \% \mathrm{Cl})\end{array}$ \\
\hline Sex & $1.30(0.58-2.89)$ & $1.36(0.54-3.41)$ & $1.01(0.52-1.96)$ & $1.36(0.59-3.15)$ \\
\hline Age & $0.99(0.96-1.03)$ & $0.64(0.25-1.64)$ & $1.00(0.97-1.02)$ & $0.86(0.37-2.03)$ \\
\hline IPF vs. non-IPF ILD & $1.65(0.71-3.88)$ & $1.52(0.57-4.06)$ & $1.27(0.64-2.53)$ & $1.05(0.45-2.46)$ \\
\hline SGRQ total score & $1.02(1.01-1.04)$ & $1.03(1.01-1.05)$ & $1.04(1.02-1.06)$ & $1.05(1.02-1.08)$ \\
\hline FVC \% predicted & $0.99(0.97-1.01)$ & $1.01(0.98-1.03)$ & $0.98(0.96-1.00)$ & $1.01(0.98-1.03)$ \\
\hline DLCO \% predicted & $0.99(0.97-1.01)$ & $1.01(0.98-1.04)$ & $0.99(0.97-1.01)$ & $1.00(0.98-1.03)$ \\
\hline mMRC & $1.61(1.03-2.51)$ & $0.83(0.42-1.63)$ & $1.83(1.22-2.73)$ & $0.65(0.34-1.25)$ \\
\hline 6-minute walk test & $1.00(0.99-1.00)$ & $1.00(0.99-1.00)^{\dagger}$ & $0.99(0.99-1.00)$ & $1.00(0.99-1.00)^{\ddagger}$ \\
\hline
\end{tabular}

DLCO = diffusing capacity of the lungs for carbon monoxide; FVC (pred \%) = forced vital capacity percent predicted; ILD = interstitial lung disease; IPF = idiopathic pulmonary fibrosis; $\mathrm{mMRC}=$ modified Medical Research Council dyspnea scale; SGRQ = St. George's Respiratory Questionnaire.

*Adjusted by sex, age, IPF vs. non-IPF ILD, SGRQ total score at baseline, FVC \% predicted at baseline, DLCO \% predicted, mMRC grade, and 6-minute walk test performance at baseline.

$\dagger p=0.053 ; \neq p=0.103$

Table 4. Factors associated with anxiety and depression at 1-year follow-up 


\begin{tabular}{|l|c|c|c|c|}
\hline & \multicolumn{2}{|c|}{ Anxiety } & \multicolumn{2}{c|}{ Depression } \\
\hline & $\begin{array}{c}\text { Unadjusted OR } \\
(95 \% \mathrm{Cl})\end{array}$ & $\begin{array}{c}\text { Adjusted OR } \\
(95 \% \mathrm{Cl})\end{array}$ & $\begin{array}{c}\text { Unadjusted OR } \\
(95 \% \mathrm{Cl})\end{array}$ & $\begin{array}{c}\text { Adjusted OR } \\
(95 \% \mathrm{Cl})\end{array}$ \\
\hline Sex & $0.85(0.43-1.68)$ & $0.82(0.35-1.91)$ & $1.06(0.55-2.02)$ & $1.13(0.52-2.47)$ \\
\hline Age & $0.84(0.42-1.70)$ & $0.74(0.31-1.77)$ & $0.89(0.46-1.73)$ & $0.66(0.27-1.60)$ \\
\hline IPF vs. non-IPF ILD & $1.49(0.70-3.20)$ & $1.48(0.54-4.10)$ & $1.93(0.91-4.09)$ & $1.69(0.64-4.50)$ \\
\hline SGRQ total score at baseline & $1.03(1.01-1.05)$ & $\begin{array}{c}1.02(1.00- \\
1.04)^{*}\end{array}$ & $1.03(1.02-1.05)$ & $\begin{array}{c}1.03(1.00- \\
1.05)^{\dagger}\end{array}$ \\
\hline FVC \% predicted at baseline & $0.98(0.96-$ & $0.99(0.97-1.02)$ & $0.98(0.96-$ & $1.00(0.98-1.02)$ \\
& $1.00)^{\ddagger}$ & & $1.00)^{\S}$ & \\
\hline $\begin{array}{l}\text { DLCO \% predicted at } \\
\text { baseline }\end{array}$ & $0.98(0.96-0.99)$ & $1.00(1.00-1.00)$ & $0.98(0.96-1.00)^{\|}$ & $1.00(0.97-1.02)$ \\
\hline mMRC at baseline & $1.98(1.22-3.23)$ & $1.25(0.60-2.61)$ & $2.22(1.43-3.45)$ & $1.29(0.58-2.61)$ \\
\hline $\begin{array}{l}\text { 6-minute walk test at } \\
\text { baseline }\end{array}$ & $1.00(0.99-$ & $1.00(0.99-1.00)$ & $1.00(0.99-$ & $1.23(0.58-2.61)$ \\
\hline
\end{tabular}

DLCO = diffusing capacity of the lungs for carbon monoxide; FVC (pred \%) = forced vital capacity percent predicted; ILD = interstitial lung disease; IPF = idiopathic pulmonary fibrosis; $\mathrm{mMRC}=$ modified Medical Research Council dyspnea scale; SGRQ = St. George's Respiratory Questionnaire.

*Adjusted by sex, age, IPF vs. non-IPF ILD, SGRQ total score at baseline, FVC \% predicted at baseline, DLCO \% predicted, mMRC grade, and 6-minute walk test performance at baseline.

${ }^{*} p=0.061 ;{ }^{\dagger} p=0.031 ;{ }^{\ddagger} p=0.05 ;{ }^{\S} p=0.047 ;{ }^{\|} p=0.02 ;{ }^{9} p=0.086 ;{ }^{* \star} p=0.016$

\section{Figures}

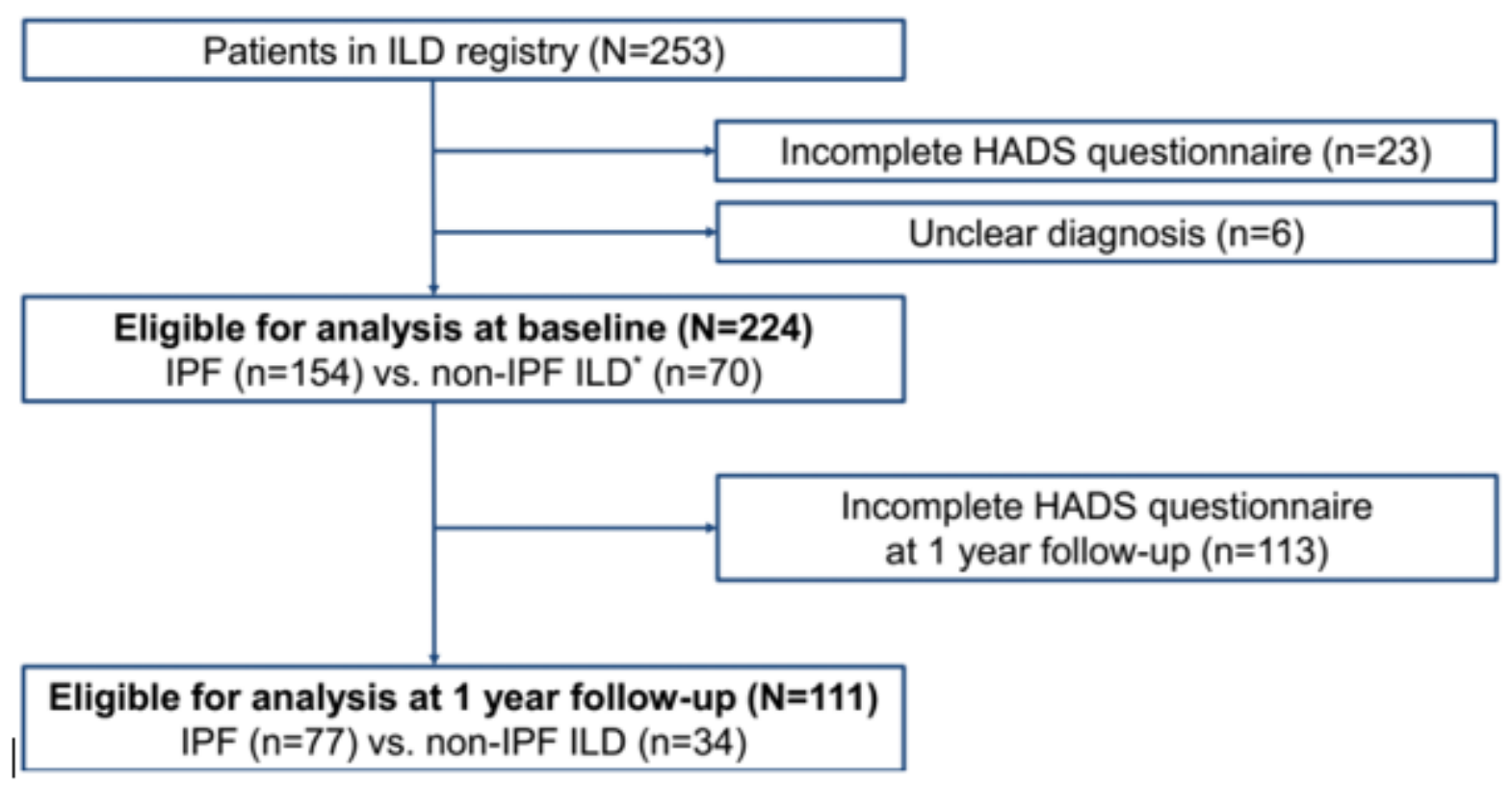

Figure 1 
Study flow chart *Non-IPF ILD were connective tissue disease-related interstitial lung disease 26 (37.1\%), nonspecific interstitial pneumonia $11(15.7 \%)$, cryptogenic organizing pneumonia 1 (1.4\%), other 32 (45.7\%). Connective tissue disease were Sjögren's syndrome 8 (30.8\%), rheumatic arthritis $6(23.1 \%)$, dermatomyositis 5 (19.2\%), systemic sclerosis 2 (7.7\%), systemic lupus erythematosus 1 (3.8), undifferentiated connective tissue disease 2 (7.7\%), mixed connective tissue disease $1(3.8 \%)$ and undiagnosed 1 (3.8\%). HADS = Hospital Anxiety and Depression Scale; ILD = interstitial lung disease; IPF $=$ idiopathic pulmonary fibrosis.

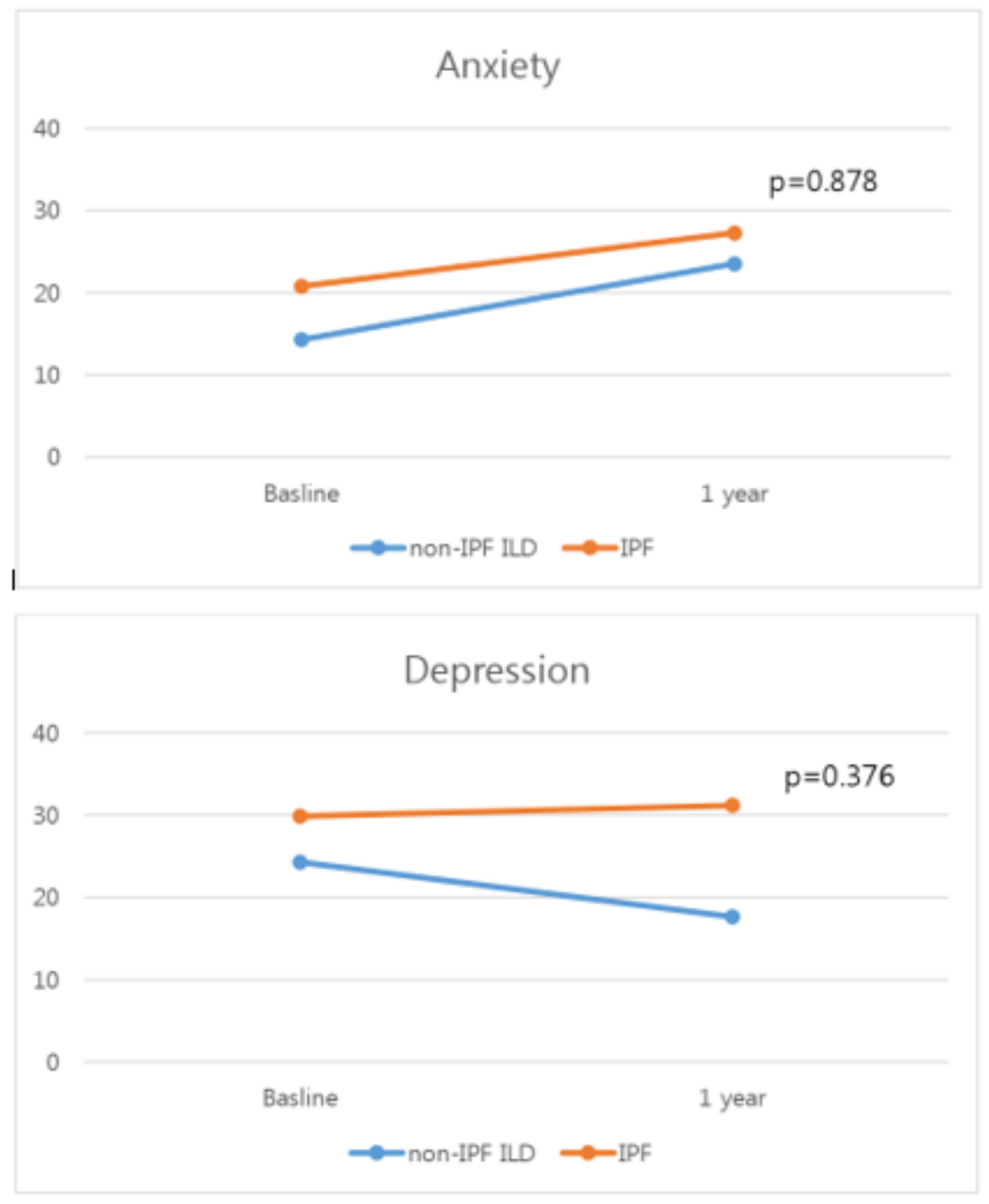

Figure 2

Prevalence change at 1-year follow-up A) Anxiety B) Depression ILD = interstitial lung disease; IPF = idiopathic pulmonary fibrosis. 